\title{
Representação Multimodal dos Atores Sociais no Discurso de Marcas
}

\author{
Multimodal Representation of Social Actors in the \\ Discourse of BRANDS
}

Neiva Maria Machado SOARES*
Josenia Antunes VIEIRA**

Resumo: O presente artigo, contemplando um diálogo teórico entre Teoria Sistêmico-Funcional (LSF) (HALLIDAY, 1994, 2004), Análise de Discurso Crítica (ADC) (FAIRCLOUGH, 1992, 2006, 2012) e Multimodalidade (KRESS; VAN LEEUWEN, 2006; VAN LEEUWEN, 2008), Marcas (GOBÉ, 2010, ALLEN; SIMMONS, 2005) e Sustentabilidade (DIAS, 2009, 2011), visa a investigar as relações discursivas e visuais estabelecidas entre os participantes do evento discurso de um texto híbrido (publicidade e informação). As teorias possuem metodologias específicas e complementares adotadas para delinear os percursos analíticos com enfoque qualitativo. A investigação evidencia que os atores sociais, visualmente representados nos textos publicitários ou informativos, são mitigados pelo poder das instituições, revelando-se não só como artifício comunicativo, mas também ideológico para cumprir prerrogativas sustentáveis.

Palavras-chave: Multimodalidade. Atores sociais. Marcas.

\footnotetext{
* Doutoranda em Linguística pela Universidade de Brasília, UnB-PPGL/IL. Mestre em Estudos Linguísticos pela Universidade Federal de Santa Maria (UFSM). Professora da Universidade do Estado do Amazonas (UEA). Pesquisadora da Fundação de Amparo à Pesquisa do Amazonas (FAPEAM). Contato: nemsoa@hotmail.com. ** Pós-Doutora em Linguística pela UnB. Doutor em Linguística Aplicada pela Pontifícia Universidade Católica do Rio Grande do Sul (1986). Pós-Doc - Universidade de Lisboa, PT (CNPq), 2001. Pós-Doc - Escola Superior de Tecnologia e Gestão Leiria - PT (CAPES), 2008. Professor Adjunto da Universidade de Brasília. Contato: josenia.unb@gmail.com.
} 
Abstract: This article, contemplating a theoretical dialogue between Systemic Functional Theory (SFL) (Halliday, 1994, 2004), Critical Discourse Analysis (CDA) (Fairclough, 1992, 2006, 2012) and Multimodality (Kress, van Leeuwen, 2006 van Leeuwen, 2008), Brands (Gobe, 2010, ALLEN; SIMMONS, 2005) and Sustainability (DIAS, 2009, 2011), aims to investigate the relationships established between visual and discursive event participants a hybrid text speech (advertising and information). Theories have specific and complementary methodologies adopted to delineate the pathways analysis with qualitative approach. Research shows that social actors, visually represented in the texts in advertising or informational texts, are mitigated by the power of institutions, revealing not only as artifice communicative, but also ideological to meet sustainable prerogatives.

Key-words: Multimodality. Social actors. Brands.

Este artigo sustenta-se em uma perspectiva transdisciplinar com afluência de posições teóricas aliadas e constituintes de significação. Assim, congregamos a teoria da Análise de Discurso Crítica- ADC, Multimodalidade, Linguística Sistêmico-Funcional (LSF), Marcas e Sustentabilidade. A ADC com orientação de Fairclough (1992, 2003, 2008, 2012) permite uma investigação transdisciplinar, porque o autor advém das Ciências Sociais, porém com um amplo conhecimento da Linguística Sistêmico-Funcional, devido à sua aproximação com Halliday (1994, 2004), assim como com a multimodalidade, via Kress e van Leeuwen (2006), van Leeuwen (2008). A inserção de marcas (GOBÉ, 2010, ALLEN; SIMMONS, 2005) e de sustentabilidade (DIAS, 2009, 2011) resulta do interesse pelas temáticas e pela possibilidade de adotar as categorias dos autores citados para entender como se constitui a construção discursiva das marcas quando o assunto é responsabilidade social e sustentabilidade.

A ADC é concebida, por um dos seus idealizadores, Norman Fairclough (1992), como área de estudo diversificada, desenvolvida como campo acadêmico distinto desde 1980. O autor tem o propósito de reunir a análise linguística e a teoria social centrada em uma combinação do sentido mais socioteórico de "discurso" com o sentido de "texto e interação" na análise de discurso orientada linguisticamente. No estágio atual, inclui um número de diferentes abordagens com a preocupação de garantir atenção mais satisfatória à pesquisa social crítica, considerando o 'discurso' como 
uma faceta da vida social, relacionado a outras facetas (FAIRCLOUGH, 2006, p. 9). Para o autor e para os demais analistas críticos de discurso, a língua é uma parte irredutível da vida social dialeticamente conectada a outros elementos da vida social.

Com essa orientação, expomos o discurso da globalização e suas implicações; o discurso empresarial transcontinental, via marcas, cada vez mais globais; o discurso do consumismo, tema tão bem explorado por Bauman (2007); o discurso das políticas socialmente responsáveis de produção e de consumo, logo, o discurso da sustentabilidade, cuja bandeira está presente em todos os recantos do planeta no final do século XX e incrementada no início do XXI. Esses temas serão exibidos na sequência, bem como a teoria de sustentação da análise.

\section{Globalização e as Várias Semioses}

Os fatores globalizantes interferem na economia, no político, no social e no ambiental e, logicamente, apresentam reflexos nas várias semioses. Para Kress e van Leeuwen (1996, p. 34), "o fluxo global do capital e da informação dissolve não somente as fronteiras culturais e políticas, mas também as semióticas". Atualmente, os textos direcionam-se da abordagem escrita e adentram o universo de práticas multimodais. No âmbito das marcas, há utilização de inúmeras semioses para interagir com o consumidor e para divulgar ideias a respeito dos produtos e conscientizá-los sobre dadas práticas.

Para Fairclough (2006, p. 3), a globalização implica:

... os fluxos, redes e interconexões são vistos com caráter diverso, e inclui por exemplo: fluxos de bens e dinheiro, rede financeira e de comércio internacional, no campo econômico; redes intergovernamentais interdependência, interação e interconexão entre agências internacionais tais como as Nações Unidas, o Fundo Monetário Internacional e a Organização Mundial do Comércio as agências governamentais nacional e regional; a mobilidade de pessoas como migrantes, turistas ou membros de organizações comerciais ou governamentais, fluxos de imagens e representações e interações através da mídia contemporânea e da tecnologia da informação. 
Assim, quantidade de informações, bens, dinheiro circulantes, em diferentes espaços e tempos, hoje, é inegavelmente superior a de anos atrás. Isso exibe reflexo na forma como nos posicionamos, como agimos, como percebemos as culturas espacialmente remotas, como são realizados e incrementados os processos produtivos, como consumimos de forma ascendente e sem controle.

Com tal olhar, o mundo mudou, logo, a globalização possibilitou a concorrência de preços, queda nos lucros, maior fragmentação da audiência dos veículos de comunicação, excesso de oferta de novos produtos com ciclo de vida mais curto forçou as empresas a serem mais convincentes em novos ambientes de consumo (GOBÉ, 2010, p. 185). A realidade nesses novos cenários compreende-se de forma diferenciada, e as marcas cada vez mais globais precisam se adaptar para continuarem presentes as vistas do consumidor exigente, atento e seletivo.

Nas novas paisagens globais, é necessário entender discurso não como constituído de uma única semiose, sim, de várias, pois inclui a linguagem escrita e a falada, combinadas com outros recursos semióticos, por exemplo, com a música na canção, com a comunicação não verbal (expressões faciais, movimentos corporais, gestos) e a imagem visual (por exemplo, fotografia, filme). Assim, o discurso é visto como um momento da prática social articulado com outros momentos não discursivos (CHOULIARAKI; FAIRCLOUGH, 1999, p. 38). O discurso vivenciado hoje, de maneira geral, parte do universo monomodal para o multimodal, cada vez mais difundido independente do gênero e do propósito comunicativo, principalmente quando se trata das marcas cuja característica acentuada é dispor de todos os recursos semióticos disponíveis para sedução constante.

Para Fairclough (2012, p. 81), "a análise do discurso está preocupada com várias modalidades semióticas das quais a linguagem é somente uma (as outras seriam as imagens visuais e a linguagem corporal)". Para o autor, a semiose é um elemento da vida social conectado a outros dialeticamente. Essas relações entre os elementos da vida social são dialéticas, pois, apesar de serem distintos os elementos analisados, eles não estão completamente separados uns dos outros. Essa orientação comprova o interesse crescente do autor por outras formas semióticas da constituição discursiva que resultam em um melhor entendimento do texto, bem como em um diálogo entre a ADC e outras teorias para propiciar um olhar mais apurado aos inúmeros contextos de produção e de consumo. 
Na Gramática do Design Visual (GDV), Kress e van Leeuwen (2006) já chamavam atenção para aspecto multimodal dos textos, em virtude de a sociedade apresentar-se cada vez mais visual. Por esse viés, dominar novas linguagens é indispensável como forma inclusive de letramento, pois a completa compreensão da linguagem possibilita leituras mais atentas nos diversos gêneros e mídias. Para os autores, "o que na linguagem é expresso por diferentes classes de palavras e estruturas das orações, pode, na comunicação visual, ser expresso pela escolha de diferentes cores ou pelas diferentes estruturas composicionais. Isso tudo afetará o sentido" (KRESS; van LEEUWEN, 2006, p. 2). Os papéis desenvolvidos pelo visual e pelo escrito são, portanto, igualmente importantes e complementares. Assim, como há uma gramática para explicar a constituição de uma língua, o mesmo ocorre com o visual, construído de forma não aleatória, tendo, assim, sua gramática também. Considerando a posição dos autores acima, a multimodalidade relaciona-se a todos os modos semióticos convergentes na composição textual, indo além do escrito.

A GDV também apresenta inovações ao contestar a arbitrariedade do signo, pois os produtores, ao selecionarem dados signos, fazem-no segundo certas intenções. Para Vieira (2012, p. 15), os produtores procuram formas mais plausíveis para representar o que é mais adequado em dado contexto. Essa perspectiva retoma a Linguística Sistêmico-Funcional de Halliday (1994) ao conceber a língua como realizada socialmente. $\mathrm{Na}$ concepção hallidayana, o uso da linguagem depende de uma série de escolhas do sistema linguístico para realizar ações específicas. Subjacentes ao uso da língua estão as metafunções ideacional, interpessoal e textual. Cada uma, respectivamente, relaciona-se com o uso da linguagem para falar de nossa experiência no mundo, incluindo o mundo interno; com a interação, ao expressar nosso ponto de vista nas coisas do mundo, para esclarecê-las ou mudá-las; com a organização da linguagem em mensagens faladas e escritas.

Kress e van Leeuwen (2006), ao considerar a similitude entre as imagens visuais e a língua, relacionam o universo das imagens às metafunções. Para eles, na função ideacional, usamos a língua para representar o mundo interno e externamente; na função interpessoal, conectamos relações e interações sociais, por exemplo, quando persuadimos o leitor de uma revista a comprar algo; na função textual, organizamos as informações visuais de forma coesa e coerente. Todas essas metafunções são complementares no uso dos signos visuais e dos signos escritos, porém, neste artigo, com foco nos atores sociais, 
recai o interesse na metafunção interpessoal, por atender como ocorre a interação entre o texto, a imagem e o observador, para estabelecer, para manter relações sociais, para difundir informações e para influenciar condutas.

$\mathrm{Na}$ teoria da multimodalidade, a linguagem é vista como forma de comunicação e de representação. Na comunicação, ressalta-se a importância de os participantes tornem suas mensagens compreensíveis dentro de contextos específicos; como representação, os produtores devem escolher formas mais aptas para expressar o pensamento em dados contextos (KRESS; van LEEUWEN, 2006, p. 13). Essa escolha por ser motivada, pode ter implicações ideológicas, pois, quando é selecionado certo signo, é excluído outro, como poderemos observar na análise a ser realizada.

Para Jewit (2009, p. 14-15), a multimodalidade descreve abordagens que entendem a comunicação e a representação indo além da linguagem, abrangendo outras formas comunicativas utilizadas como: gesto, postura, imagem e olhar, considerados como modos comunicativos, bem como a relação entre eles, moldados social, cultural e historicamente. Os significados são construídos na seleção e na configuração desses modos.

A multimodalidade parte da posição de que todos os modos, como o falado e o escrito, constituem-se de um conjunto de recursos semióticos, e os modos e os recursos escolhidos são determinantes de significação. A escolha dos modos semióticos não é aleatória, assim, a cada época as pessoas podem selecionar aqueles que cumprem os propósitos exigidos para a comunicação. No contexto social e cultural atual, as novas mídias convergem no sentido da usualidade de infinitos modos semióticos para atrair leitores, consumidores e seguidores.

Considerando a temática deste artigo, os recursos multimodais são importantes, pois a constituição discursiva das marcas relaciona-se com os múltiplos modos semióticos como forma de constituir e de reforçar dada imagem para seus públicos.

Na mesma direção, no livro The language of colour, van Leeuwen (2011) estabelece relação entre as metafunções e as cores:

No aspecto ideacional, as cores podem ser utilizadas para denotar de forma específica ou genérica lugares, coisas, classes e pessoas [...]; No interpessoal, assim como a linguagem permite realizar atos de fala, as cores permitem realizar atos de cores [...]; no textual, também podem ser usadas para criar coerência entre os diferentes elementos de um todo ou para distinguir as partes. (van LEEUWEN, 2011, p. 11). 
$\mathrm{Na}$ citação, o autor atenta para o aspecto visual e comunicativo das cores, pois são tão representativas na comunicação ao ponto de uma única cor sinalizar uma ou mais informações sem dispor de nenhum outro recurso semiótico. A identidade das marcas alicerça-se nas cores, e podemos reconhecê-las pelo que uma cor comunica em primazia aos demais signos.

\section{Marca, Identidade e Sustentabilidade}

Nos anos 1980, o termo "marca" migrou dos detergentes em pó e passou a significar praticamente qualquer coisa com capacidade de atrair e de influenciar (ALLEN; SIMMONS, 2005, p. 133). Assim, hoje a marca vai desde o nome de uma celebridade, de um partido político, a tabletes de chocolates, ou seja, afasta-se do universo empresarial e adentra no pessoal ou no profissional.

Em linha similar, para Fairclough, (2006, p. 102), a marca tornou-se uma indústria global, com seu próprio aglomerado de especialistas altamente remunerados, consultores de branding espalham a mensagem da marca em todo o mundo. A ideia de marca foi originalmente aplicada a bens comerciais no sentido tradicional (por exemplo, sabão em pó), mas foi estendido para bens menos tangíveis (como a marca cosmo revista feminina Cosmopolitan). A técnica de branding baseia-se em princípios simples: marca deve refletir pontos fortes, compromissos e valores. Para o autor, marca constitui-se uma promessa para o cliente e deve sempre comunicar valores nas ações e nos comportamentos.

A identidade visual de uma marca engloba os componentes gráficos cujo sistema permite identificar e representar a marca, tais como: logotipos, símbolos, cores e tipos de letras. Impossível pensar em certas marcas e não remeter, por exemplo, ao vermelho no caso da Coca-Cola, aos arcos no caso do McDonald's (ALLEN; SIMMONS, 2005, p. 134). Essa percepção ressalta a importância da modalidade visual e associa-se àquela desenvolvida por Kress e van Leeuwen (2006) ao relacionar o visual tanto como forma de representação como de comunicação. Aliada à identidade visual, há a identidade no traço verbal da marca, representado pelo nome, suficientemente forte para ser lembrado, pelo lema, mutável de acordo com a campanha publicitária, pelo tom de voz, pois certos produtos fazem questão de atribuir um tom de acordo com a finalidade, mais forte no caso de propaganda de carro, mais sedutora para perfumes e joias. Isso pode ser verificado na citação, a seguir: 
Qualquer empresa, produto ou serviço não conseguirá progredir se não conseguir mostrar do que se trata e porque é diferente. Mostrar isso significa ter o objetivo por de trás da forma como os nomes são criados e usados, da criação de logotipos e de símbolos, da utilização de cores e do tipo de letra, da ilustração e da fotografia, do padrão, do estilo e do uso da linguagem. (ALLEN; SIMMONS, 2005, p. 136).

A identidade diferencia uma marca da outra e a faz ser mais ou menos lembrada, para que isso ocorra, é indispensável ter propósitos claros e a divulgar constante. Isso se confirma em ações e em produtos adequados às necessidades dos consumidores, tornando-os fiéis à marca, inclusive na propagação de valores agregados aos produtos ofertados e adquiridos (Figura 1).

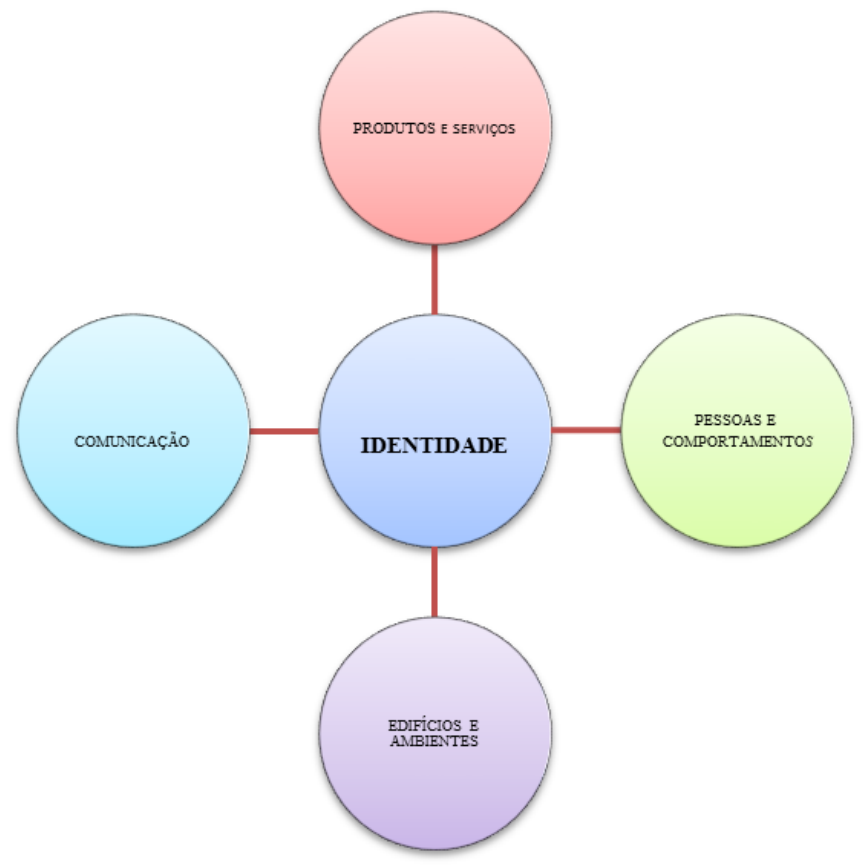

Fonte: ALLEN; SIMMONS, 2005, p. 136.

Figura 1 - Percepção da identidade de uma marca 
Pela reprodução acima, identidade engloba fatores imprescindíveis para todas as marcas como o espaço físico e a forma como os funcionários procedem, pois são tão importantes quanto os produtos expostos nas grandes lojas. Assim, não só uma bela propaganda na revista ou internet, mas também o engajamento e o comprometimento de pessoas com a missão da empresa são elemento que sustentam e reafirmam a identidade das corporações.

A marca, no contexto de século XXI, passou a ser cobrada em inúmeros quesitos, entre eles a responsabilidade social e, por conseguinte, a responsabilidade ambiental, porque, além de produzir, as empresas precisam estar conscientes de suas responsabilizadas pelos danos causados ao meio de atuação. Quando se menciona o termo produzir, muitos pensam no efeito ascendente, por exemplo, no incremento do PIB ou na possibilidade de um maior número de empregos para a população, porém, no contexto atual de esgotamento de recursos naturais em todo o mundo, o tipo de produção predatória está com os dias contados. Eventos como Rio+20 nos fazem refletir sobre responsabilidade social e as três implicações: social, econômico e o ambiental. A Figura 2, a seguir, sinaliza o esperado de uma empresa sustentável, com uma produção de acordo com essas prerrogativas.

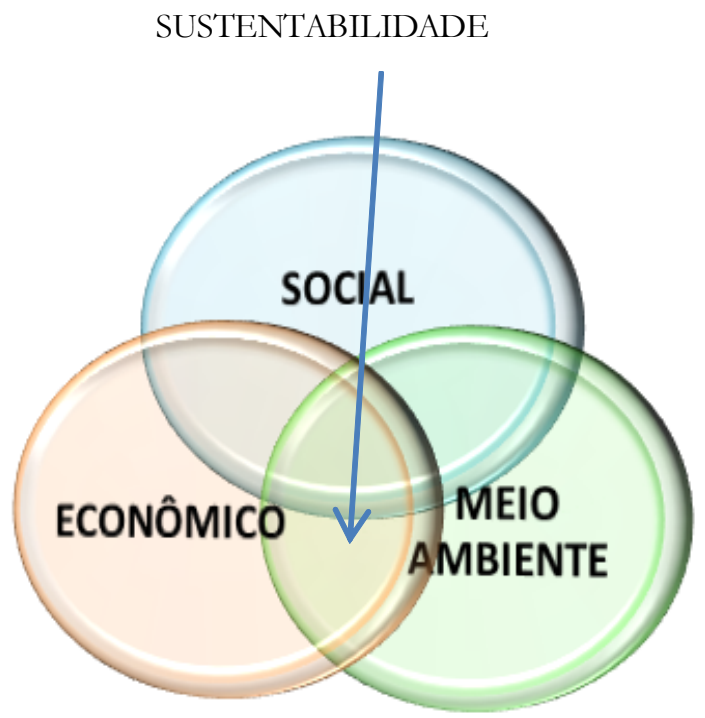

Fonte: DIAS, 2009.

Figura 2 - Fatores da sustentabilidade 
Sustentabilidade, como indica a seta, corresponde à confluência de três fatores: social, ambiental e econômico. O maior desafio é a relação entre o econômico e o ambiental, pois, no contexto de sociedade capitalista, alicerçada em padrões de consumo, o econômico incorpora relevância preponderável. Da mesma forma, o social muitas vezes é preterido, pois o esperado é que o econômico seja a solução para todas as questões.

Fairclough também se posiciona quanto ao crescimento econômico e à sustentabilidade:

... questionar o crescimento econômico como um valor ainda é uma coisa escandalosa na maioria dos contextos e dos países. Por outro lado, a ideia de 'limites de crescimentó tem sido amplamente integrada de modo superficial na política oficial, que é muito influenciada agora pelos economistas e pelos políticos para definir seus objetivos como crescimento sustentável. Mas os críticos argumentam que as políticas que têm sido desenvolvidas em nível nacional e internacional para alcançar sustentabilidade nem sequer começam a abordar o que seria necessário para o estado de equilíbrio global previsto. (FAIRCLOUGH, 2006, p. 58).

O autor explana sobre a discussão do momento: como continuar consumindo e produzindo quando os recursos naturais do planeta estão cada vez mais reduzidos, ou quando em muitos países, como a China, o índice de poluição é altíssimo impedindo as pessoas de respirar sem alguma forma de proteção. Assim, os ideais propostos, ao se tratar de sustentabilidade, são louváveis, porém situam-se apenas no discurso, pois as práticas estão cada vez mais voltadas para o crescimento de índices como PIB, baseados apenas no crescimento econômico.

Justificamos a importância acerca do tema em estudos linguísticos com as palavras de Fairclough (1996, p. 24),"mudanças no uso linguístico são uma parte importante de mudanças sociais e culturais mais amplas". Assim, no momento em que as marcas começam a valer-se da questão da sustentabilidade em seus discursos, é relevante, como pesquisador e como linguista, entender como se constroem essas práticas mercadológicas, como forma de perceber o processo econômico e, por consequência, a sociedade consumista contemporânea. Dessa forma, compreender a sociedade e sua forma de agir é um grande desafio para todo o pesquisador, principalmente quando isso suscita uma tranformação discursiva. 
Visando, portanto, provocar uma reflexão sobre a temática ambiental aliada ao discurso de marca, o escopo deste artigo é a constituição discursiva da marca Coca-Cola Brasil com base na representação visual de atores sociais em dois textos publicitário-informativos, extraídos dos sites, cujos temas são: Cada garrafa tem uma história e Semana otimismo que transforma. A empresa possui a plataforma Viva Positivamente onde reúne informações sobre eventos relacionados aos três quesitos da sustentabilidade: no econômico, no social e no ambiental. Desse ambiente, extraímos dados para também sustentar a análise. A metodologia empregada é a qualitativa, tendo como suporte as categorias da Multimodalidade, atores sociais de van Leeuwen (2008), Análise de Discurso Crítica e dos pressupostos da teoria da Sustentabilidade e das Marcas.

\section{Contextualizando a Análise}

Os textos apresentados, na sequência, utilizados nesta análise, apresentam uma configuração genérica singular, tal percepção leva-nos a não considerá-los como parte de um único gênero, devido à estrutura textual bastante complexa, com múltiplos recursos visuais e discursivos. Assim, podem ser considerados como híbridos na sua constituição multimodal, bem como discursiva. O artigo tem como proposta analítica o visual, porém para analisar as representações visuais, julgamos necessário um levantamento dos aspectos discursivos, como afirma van Leeuwen, esse aparato teóricometodológico pode ser substancial para o âmbito visual e para o discursivo. Os textos 1 e 2, a seguir, fazem parte da política de sustentabilidade da marca Coca-Cola Brasil, visam divulgar ações da empresa nesse quesito, bem como as parcerias estabelecidas, foram extraídos do site da Coca-Cola Brasil. Podem ser identificados como a configuração de uma nova constituição discursiva com a emergência de um discurso híbrido de informação-publicidade (ou falar e vender) (FAIRCLOUGH, 1992). 


\section{Texto 1 - Cada garrafa tem um história- Marcos André}

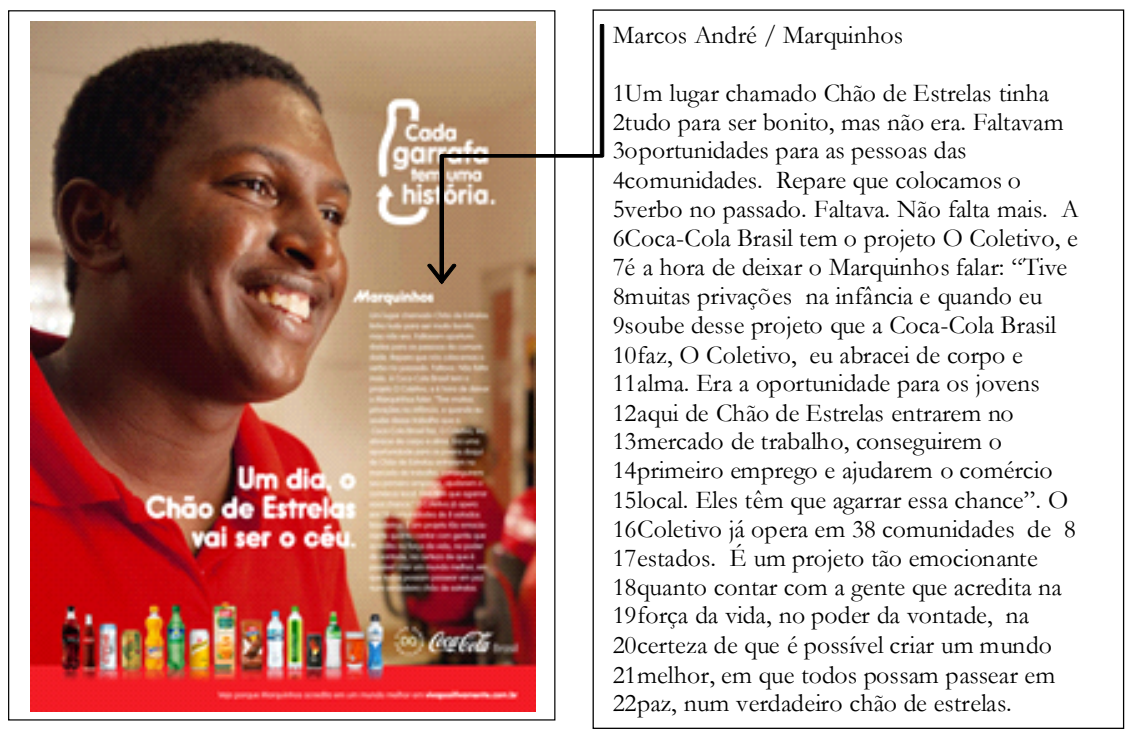

Fonte: Disponível em: <http://www.coletivococacola.com.br. Acesso em: 12 jan. 2012.

Observamos, no texto 1 , uma multiplicidade de recursos comunicativos, com um destaque para texto visual, com personagens Marquinhos e os produtos da Coca-Cola Brasil -, além do texto escrito com remissão a esses participantes. O título cita Marquinhos, participante maior, porém, na linha 6, surge outro participante a Coca-Cola Brasil e o seu projeto $O$ Coletivo. Assim, se o intuito era apresentar Marquinhos, a sua voz se diluiu em meio às demais informações. As linhas 7 a 15 destinam-se às palavras de Marquinhos: Tive muitas privações na infância [...], mas com uma nítida orientação de publicidade, com léxico encaminhando para o discurso da Empresa com os termos: projeto, oportunidade, mercado de trabalho, comércio. Há um direcionamento para o papel social da Empresa ao enfatizar: Eles têm que agarrar essa chance (linha 15), remetendo aos demais moradores da comunidade. $\mathrm{Na} 16$, surge o outro participante, o Coletivo, projeto da Empresa. Assim, Marquinhos é um ator, que vem apresentar outro que é o Coletivo, que, por sua vez, fazem parte do grupo do participante dominante Coca-Cola Brasil. Na conclusão do texto, há apelo para o aspecto emocional, 
por parte da Coca-Cola Brasil, na forma de uma metáfora interpessoal, linhas 21-22, é possivel criar um mundo melhor[...]. Para, em seguida, retomar Chão de Estrelas estabelecendo uma relação metafórica com o local onde o projeto atua.

Há igualmente, no texto, uma relação intertextual ao citar um depoimento de Marquinhos: "Quando eu soube do projeto Coletivo, da Coca-Cola Brasil, acreditei que poderia ser um multiplicador de sonhos, abracei de corpo e alma. Era a chance para jovens daqui transformarem suas vidas, conseguirem seu primeiro emprego e ajudarem o comércio local" (linhas 9-15). Embora esse discurso seja atribuído ao ator citado (primeira pessoa do singular), não há como saber se ele não foi modificado ao ser incluído pelo produtor do texto, observamos um possível alinhamento entre o discurso de Marcos André e o discurso da Empresa em que ele é o indivíduo ajudado pelo projeto da marca. Nesse caso, a Empresa passa de ator coadjuvante a ator principal. Existe ainda uma relação interdiscursiva, entre o discurso econômico da Empresa/marca e o discurso do personagem cuja saliência poderia ser maior.

\section{Texto 2 - Semana Otimismo que transforma - Tião dos Santos}

Tião dos Santos
1A história do Tião foi acreditar que através da
2reciclagem dava para transformar a vida de
3catadores. Acreditou tanto num futuro melhor, que
4hoje é o presidente da associação dos catadores do
5Jardim Gramacho. Com o apoio as histórias como a
6do Tião, a Coca-Cola Brasil contribui com mais de
7/200 cooperativas, promovendo inclusão social e
8gerando renda para mais de 6.000 famílias.
9 Entre os dias 20 a 27 de maio todos os produtos da
10Coca-Cola Brasil que você beber vão ajudar a
11criar novas histórias, como a do Tião. É que toda
12embalagem vendida vai gerar uma doação para o
13projeto de reciclagem do Instituto Coca-Cola
14Brasil. Só no ano passado foram doados 5
15milhões de reais. Para ajudar a superar essa
16marca, participe e faça parte dessa história. Quer
17saber como.
Acesse. www.cocacolabrasil.com.br

Fonte- Disponível em: $<$ http//www.semanaotimismo.com.br $>$. Acesso em: 3 maio 2012. 
No texto acima, igualmente, há uma mescla entre informação e publicidade, pois, ao mesmo tempo em que informa sobre os projetos sociais da Coca-Cola Brasil: [...] Coca-Cola Brasil contribui com mais de 200 cooperativas, promovendo inclusão social e gerando renda para mais de 6.000 familias (linhas 6-7), também tenta vender produtos da marca: os produtos que você beber vão ajudar a criar novas histórias como a de Tião (linhas 10-11). Há troca de bens e serviços quando propõe aos consumidores: participe da semana otimismo que transforma e faça parte dessa bistória (linha 16); ou pelo comando: Acesse (linha 17); sugerindo o site da Empresa. $\mathrm{Na}$ ótica multimodal, os textos também podem ser considerados como híbridos porque contêm inúmeras semioses que trazem vida à publicidade, deslocando-se do verbal para o visual em diferentes modos de composição.

Observa-se, ademais, a alternância das frases entre o discurso empresarial e o social, sendo que algumas podem ser atribuídas a um ou a outro; outras, porém, são ambivalentes. Há a intenção de dar voz a quem socialmente pode ser visto como aquele que não a possui, porém o poder e a ideologia da marca abarca todo o discurso. Ao considerar o discurso sustentável, há três direções, a saber, social, ambiental e econômico. Apesar de a Empresa ter "dado" voz aos dois participantes, é nítida a preocupação de demonstrar a atuação no mercado, bem como a partição na economia, sendo, assim, o social e o ambiental elementos adicionais ou ilustrativos.

Após a contextualização dos dois textos a serem analisados, neste estágio, encaminhamos para o tema principal foco do artigo - análise dos atores sociais.

\section{Análise da Relação Atores Sociais e Observadores}

Nesse aspecto, o suporte analítico detém-se em Discourse and practice: new tools for critical discourse analysis (2008) de Theo van Leeuwen, que constitui um aparato metodológico para análise de textos visuais e escritos. As ferramentas oferecidas pelo autor possibilitam a reconstituição dos discursos e a demonstração de como os mesmos reforçam e representam as práticas existentes na sociedade. Com a análise de textos, é possível verificar também como esses se valem e se transformam em práticas sociais, ao reproduzirem o que ocorre em muitos contextos sociais.

Analisaremos, dessa forma, a forma como os participantes das práticas sociais, no discurso da marca em questão, podem ser representados 
visualmente no discurso, seguindo as orientações metodológicas propostas van Leeuwen (2008), Quadro 1.

Quadro 1 - Representação da Imagem e do viewer. Atores sociais e observadores (AS/OBS)

\begin{tabular}{|c|c|c|c|}
\hline \multirow{4}{*}{$\begin{array}{l}\text { Representação: } \\
\text { Imagem e } \\
\text { viewer. }\end{array}$} & DISTÂNCIA & $\begin{array}{l}\text { - } \underline{\text { Próxima }} \\
\text { (plano fechado) } \\
\text { - Distante } \\
\text { (plano aberto) }\end{array}$ & \\
\hline & & - Envolvimento & $\begin{array}{l}\text { Envolvimento: } \\
\text { ângulo frontal } \\
\text { Distanciamento: } \\
\text { ângulo elevado }\end{array}$ \\
\hline & RELAÇÃO & - Poder & $\begin{array}{l}\text { Poder do } \\
\text { observador (ângulo } \\
\text { alto) } \\
\text { Igualdade (nível do } \\
\text { olhar) } \\
\text { Poder de } \\
\text { representação } \\
\text { (ângulo baixo) }\end{array}$ \\
\hline & INTERAÇÃO & & $\begin{array}{l}\text { Endereçamento } \\
\text { direto: a pessoa } \\
\text { olha para o viewer } \\
\text { Endereçamento } \\
\text { indireto: a pessoa } \\
\text { não olha para o } \\
\text { viewer. }\end{array}$ \\
\hline
\end{tabular}

Fonte: Elaboração das autoras, baseadas em van Leeuwen, 2008. 
Ao propor tais categorias analíticas, Van Leeuwen (2008) assevera que dada cultura não tem maneira própria de representar o mundo social, mas uma maneira particular de mapear os diferentes modos semióticos, dentro dessa ordem, descrevendo o que pode ser realizado verbal e visualmente.

Para analisar a representação da Imagem e do Viewer no discurso da marca, a seguir, tomamos as mesmas imagens apresentadas anteriormente, agora consideradas em conjunto, de acordo com as categorias elencadas acima.

Imagem 1

Imagem 2

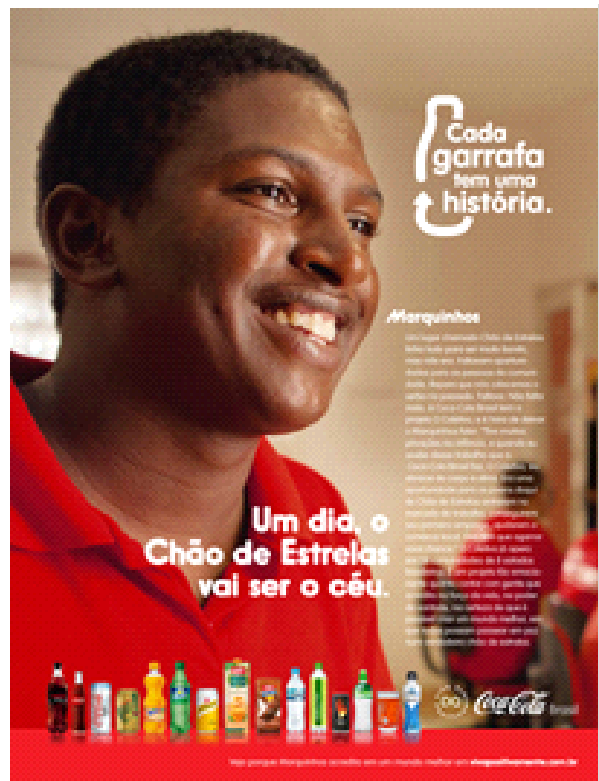

Fonte: Disponível em: <http:// Fonte: Disponível em:<http// www.coletivococacola.com.br. Acesso em: 12 jan. 2012. www.semanaotimismo.com.br $>$. Acesso em: 3 maio 2012.

O contato visual, nas duas imagens, é estabelecido no nível da oferta, Marquinhos e Tião não olham, nem se dirigem ao espectador, não há nenhum tipo de contato visual, o viewer é quem os observa. A Imagem 1 não possui um vetor entre observado e observador. $\mathrm{Na}$ Imagem 2 , há demanda quando 
os "prováveis" consumidores mantêm um contato com os espectadores por meio de um vetor, nesse caso, um produto da marca. Ademais, há troca de atividade (bens e serviços) pela demonstração e pela oferta dos produtos da marca.

A composição dos itens discursivos e linguísticos propicia uma mescla entre troca de atividade e troca de conhecimento. Atividade está na propaganda e na intenção de demostrar o realizado no aspecto da responsabilidade social: toda embalagem vendida vai gerar uma doação para o projeto de reciclagem do Instituto Coca-Cola, ao mesmo tempo em que fornece informação sobre a existência do programa. Logo, há composição entre publicidade e informação, caracterizando-se como um texto híbrido, nesse caso, publicidade disfarçada com texto informativo.

Nas duas imagens, a distância social, no plano fechado, sugere intimidade e tenta instituir uma familiaridade entre os participantes, observado e observador. Exibe a cabeça e os ombros, o que aproxima e proporciona um contato não pelo olhar, mas pela observação de características não perceptíveis no plano aberto. Essa "possível" intimidade parece ser meio forçada, pois a vestimenta dos participantes estabelece uma nítida relação entre ele e a Empresa, levando o espectador a associar a cor da roupa à cor da marca. O Close-up, para van Leeuwen (2008), lembra que as pessoas são como um de nós.

No plano fechado, Imagem 2, também estão os diferentes personagens selecionados pela marca para incentivar outras pessoas a publicarem suas atitudes positivas ao consumir um produto, todos têm em mão um tipo de produto da linha. Quanto ao distanciamento, no plano aberto, aparecem os vários produtos, Imagem 1, da marca Coca-Cola Brasil, indicando a participação como coadjuvantes ou não.

Quanto ao envolvimento, os dois participantes analisados, nas duas imagens, estão no ângulo oblíquo, ou seja, em uma relação de distanciamento, logo, estão apenas sujeitos à observação.

Quanto ao poder, Marcos André/ Marquinhos está no ângulo elevado, para van Leeuwen, significa que o ator tem um poder simbólico sobre o viewer, porém, nesse caso, o poder não está representado apenas no ator Marcos, mas sim, no ator maior, a marca Coca-Cola Brasil.

Em relação à interação social, por um lado, há um endereçamento direto, se considerarmos a Coca-Cola Brasil, o logotipo, o design da garrafa, os produtos e a cor dominante em boa parte da página, associados à 
identidade da marca; por outro, endereçamento indireto, pela posição em que foram retratados Tião e Marcos André, pois não se estabelece contato (olhar) entre o observador e o observado.

\section{Categorização visual dos atores sociais}

Quanto à categorização dos atores sociais, esses podem ser retratados como excluídos e incluídos (Figura 4, abaixo). Van Leeuwen (2008) considera a exclusão, importante para a análise, pois todas as práticas envolvem um conjunto de atores sociais que podem ser inseridos ou excluídos do texto (linguístico). Os atores sociais podem ser retratados de forma genérica ou específica, como uma classe de indivíduos ou de forma genérica como pessoas comuns. Quanto à assimilação, essa se dá pela agregação e pela coletivização. A individualidade relaciona-se à singularidade; a assimilação, à pluralidade. A associação e a dissociação são formadas por e de atores sociais que nunca são indicados no texto. Indeterminação e diferenciação, pelos atores anônimos. Nominação e categorização, pela identidade. Ocupação e identificação, pelos nomes que denotam ocupação, atividade e gênero. Funcionalização e identificação, pelos atores sociais são referidas em termos de sua atividade. A classificação é constituída pela idade, pela classe, pelo sexo, pela cor e pela raça. Os atores podem ser retratados pela personalização e pela impersonalização. Van Leeuwen (2008) observa que a rede de representação dos atores sociais traz junto o que os linguistas tendem a manter separado, envolve número de distintos sistemas lexicogramaticais e de níveis linguístico-discursivos, de transitividade, de referência, de grupos nominais, de figuras retóricas, porque esses sistemas estão envolvidos na realização da representação dos atores sociais (Figura 4). 


\section{$\underline{\text { Exclusão }}$}

Categorização

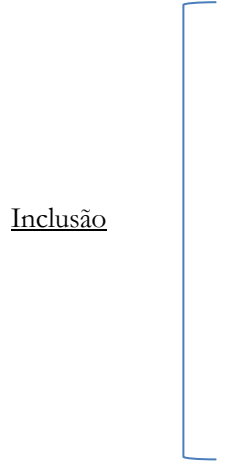

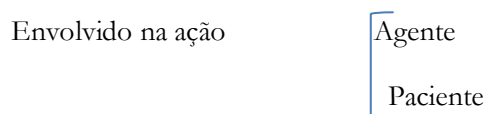
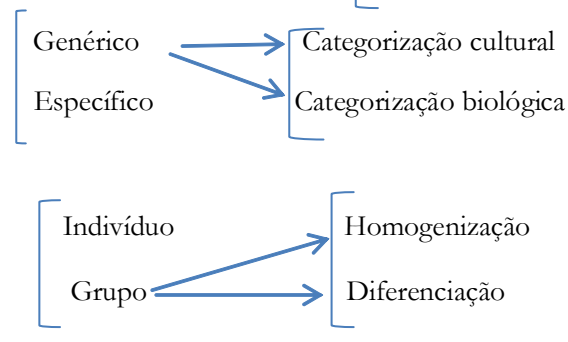

Fonte: Elaboração das autoras, baseadas em van Leeuwen, 2008.

Figura 4 - Categorização dos Atores Sociais (AS)

As categorias apresentadas, na Figura 4, concebidas por van Leeuwen, auxiliam na verificação de como a marca constrói relações com o público, como os atores sociais são apresentados, qual a importância atribuída ou não aos diferentes atores do discurso.

Quanto à categoria de exclusão e inclusão, os atores, nas imagens $1 \mathrm{e}$ 2 (na página seguinte), Marquinhos e Tião, podem ser analisados como inclusos, ora como agentes, ora como pacientes. Marquinhos, por um lado, é considerado como agente por ser protagonista de uma história; por outro, como paciente, pois a sua história serve de pano de fundo para a do agente maior. No caso de Tião, participante com imagem no centro da publicidade, há uma mescla entre esse ator e os diversos outros atores, provavelmente simulam ações de possíveis consumidores, instigando o público a fazer o mesmo. Assim como Marquinhos, Tião pode ser visto como agente e paciente. Agente por ser a pessoa conhecida no contexto da reciclagem e por aparecer no centro da imagem; paciente porque serve de ilustração para que a Coca-Cola Brasil se pronuncie sobre atividades consideradas em prol do social. Assim, a marca é um agente inegável em todo o texto, na forma verbal e na forma visual, participante mentor das ações e das histórias divulgadas. Se víssemos apenas por esse ângulo, Tião e Marquinhos poderiam ser tratados como pacientes e a marca o agente máximo. 


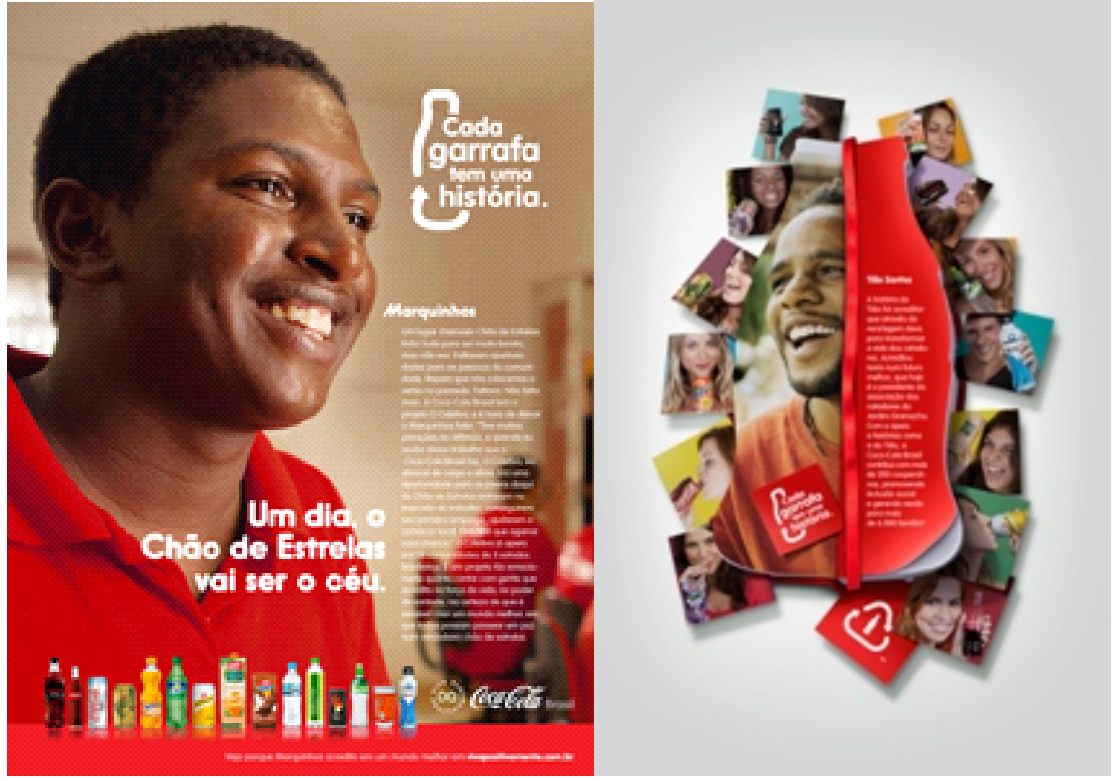

Fonte: Disponível em: <http:// Fonte: Disponível em:<http// www.coletivococacola.com.br. Acesso em: 12 jan. 2012.

www.semanaotimismo.com.br $>$. Acesso em: 3 maio 2012.

A inclusão dos atores retratados ocorre de forma específica e genérica. Específica, ao citar o nome de cada personagem, a Empresa identifica-os como indivíduos de dado local; genérica, quando os apresenta como parte de um grupo da sociedade- os catadores- de pessoas sem outras escolhas a não ser viver daquilo expurgado pela sociedade de consumo. Quanto a aspectos culturais e biológicos, na imagem analisada, o cultural refere-se a um grupo de brasileiros excluídos do acesso à cultura, por isso, realiza trabalhos que a maioria das pessoas se nega a fazê-lo; o biológico, ao fato de ambos serem negros é relevante, pois os consumidores que ladeiam a foto de Tião são, em sua maioria, brancos, no entanto, os catadores não são. Assim, Tião está no centro, mas não se insere no grupo próximo a ele.

Há uma representação na forma individual e também em grupo dos indivíduos Tião e Marcos André. Tião é catador, exerce o papel de ator social como indivíduo, mas também faz parte de um grupo da cooperativa 
de catadores do antigo Jardim Gramacho. Da mesma forma, Marcos André é identificado como uma das pessoas com uma história para contar, porque conseguiu superar as adversidades e se tornou um agente em sua comunidade, podendo auxiliar outras pessoas do seu grupo. O personagem Tião tem sua imagem constantemente associada aos projetos sustentáveis da empresa, sendo um dos atores do documentário indicado ao Oscar, 2009 - Lixo Extraordinário, Tião participa de comerciais da marca, patrocinadora oficial da Copa do Mundo.

$\mathrm{Na}$ caracterização do grupo, eles podem ser homogêneos e diferenciados. Homogêneos porque há um grupo do qual os dois atores citados fazem parte, como pessoas que superam as dificuldades com o auxílio da marca; diferenciados porque pertencem a um grupo minoritário cuja biografia os identifica e os diferencia dos demais.

$\mathrm{Na}$ imagem em que Tião está retratado, também podemos citar os demais atores na composição da cena, há homogeneização entre si, pois todos são jovens, bonitos, aparentam estar felizes consumindo produtos da marca Coca-Cola Brasil, ou seja, sugere-se que, com essa prática, possibilitam à empresa ajudar pessoas como o próprio Tião, estão unidos e identificados devido ao produto consumido.

A análise demonstra a importância dos modos semióticos e visuais na comunicação na sociedade. Nas imagens, significante e significado, ou seja, o signo é socialmente motivado (KRESS; VAN LEEUWEN, 2006). As informações visuais ou não são estrategicamente pensadas para criar estímulos nos viewers. No caso em apreciação, utilizados não só para dar visibilidade aos projetos da marca, mas também para reforçar a identidade de empresa como parceira e como sustentável, porém muito ainda precisa ser feito para considerar as empresas como colaboradoras do meio ambiente em sua totalidade. Outros atores estratégicos poderiam passar a fazer parte desse processo como a sociedade, o governo e as ONGs, principalmente, para estabelecer metas, parcerias e projetos mais efetivos. Dessa forma, as práticas poderiam se tornar mais sólidas, permitindo ir além de um discurso bonito e verde.

Para concluir essa análise, ainda no âmbito da teoria multimodal, julgamos significativo ressaltar o papel das cores na constituição discursiva da análise dos atores sociais. 


\section{Os Atores e os Atos Discursivos de Cores}

A teoria da cor deve ser capaz de conectar forma e significado e de explicar como os recursos da cor e de seus usos estão socialmente estruturados para permitir o tipo de expressão cultural e comunicação social de que a sociedade necessita (VAN LEEUWEN, 2011, p. 40). As imagens conduzem ideologias (KRESS; VAN LEEWEN, 2006) de seus produtores, no caso analisado, fica evidente a presença da Coca-Cola Brasil, representada na própria imagem de cada um dos participantes. Para van Leeuwen (2011), as cores, como recursos semióticos, têm função social nos diversos contextos. Assim, podem associar-se às metafunções da linguagem: textual, interpessoal e ideacional.

\subsection{A metafunção textual nas cores}

A cor poder ser empregada textualmente, para criar coesão e coerência entre os diferentes elementos de um todo ou entre as partes distintas de um texto (VAN LEEUWEN, 2011, p. 11). Os personagens em destaque, nas imagens 1 e 2, harmonizam-se com a cor vermelha da marca, sugerindo apelo à vida, ao amor e à paixão. A imagem de Marcos André com a camisa vermelha representada no plano fechado funde-se com o vermelho dos produtos da marca e com o logotipo da empresa, como se o personagem fosse uma extensão da marca.

\subsection{A metafunção interpessoal nas cores}

A cor pode ser utilizada para transmitir significados interpessoais, pois assim como a linguagem nos permite realizar atos de fala, a cor, atos de cor (VAN LEEUWEN, 2011, p. 11). A cor é recurso semiótico para a construção de significados, na interação entre os personagens e o público, contribui para a troca de mensagem entre a os atores apresentados e o consumidor ou viewver. Pela cor vermelho, é possível associar a pessoa citada como alguém que tem uma função no grupo Coca-Cola Brasil. O vermelho é significativo para a Coca-Cola e para os seus consumidores, pois, em dados contextos, uma simples menção já proporciona a interação entre a marca e os seus produtos com o consumidor. 


\subsection{A metafunção ideacional das cores}

Os textos também constroem nossas visões sobre o mundo. Para van Leeuwen (2011), a cor pode denotar pessoas, lugares e coisas bem como classe de pessoas, lugares e coisas e ideias mais gerais, pode ser associada como marca da identidade de um país, de um grupo ou de um time. No texto analisado, a imagem da Empresa associada à cor vermelha é sempre lembrada em inúmeros países, como símbolo de paixão ou até de rebeldia. Assim, ao associar os personagens à cor vermelha sugere o apelo ao consumo de um produto que fez e faz parte do imaginário de muitas pessoas de países capitalistas ou não, inclusive no Brasil, terceiro maior mercado consumidor da marca, depois dos Estados Unidos e da China. A bebida desperta tanta curiosidade que em muitos países chegou a ser vendida de forma clandestina, em tempos globalizados, talvez já não mais ocorra.

As marcas, sabedoras de que as cores podem despertar diversos sentimentos, agradáveis ou desagradáveis, de prazer ou de dor, relacionados diretamente ao emocional e ao racional, usam disso para influenciar o comportamento do consumidor e levá-los a se tornarem os maiores ícones da marca.

\section{Considerações Finais}

Nessas novas paisagens multisemióticas e multidiscursivas, a sociedade, com seus inúmeros atores sociais, começa a utilizar o seu poder de ingerência no mercado. A temática ambiental, antes restrita a um pequeno grupo, principia a marcar presença em todos os âmbitos. As empresas, grandes vilãs, e sabedoras do poder social, estabelecem parcerias para se tornarem socialmente responsáveis, associam-se, assim, a personagens como Tião e Marquinhos. O emprego de dois atores negros não é somente um caso de responsabilidade social, sim, porque as marcas devem aumentar o poder de personalização, aplicada a diferentes orientações culturais e crenças, reconhecendo grupos étnicos, gêneros, idade (GOBÉ, 2010). A participação desses vem também de uma demanda da própria sociedade brasileira, que é multicultural, também uma das prerrogativas de práticas que se adequam à responsabilidade social.

Quanto aos três princípios da sustentabilidade: social, econômico e ambiental, a Empresa visou destacar o social, por meio dos projetos de inserção de grupos minoritários. Percebemos que nas imagens Tião e de 
Marquinhos são retratados com saliência nas fotos, porém sempre com a presença da marca como ator maior. É visível o poder econômico, principalmente na relação decrescente: consumo-projeto-reciclagem. Nos casos citados, todos os participantes dependem uns dos outros, pois, ao mesmo tempo em que contribui com meio ambiente, a marca auxilia pessoas de baixa renda a terem um retorno financeiro. Esses indivíduos também carecem do apoio da Empresa porque têm na atividade talvez a única fonte de renda. Logo, há uma cadeia, a marca é cobrada para dar um destino adequado aos seus dejetos, e os catadores necessitam desse "trabalho" como fonte de sustento. A Empresa é a maior beneficiada, embora tente demonstrar de forma diferente. Assim, as empresas engatinham para o social e o ambiental, mas com suas "garras" bem presas ao econômico.

\section{Referências}

ALLEN, T.; SIMMONS J. Identidade visual e verbal. In: CLIFTON, R.; SIMMONS, J. (Orgs.). O mundo das marcas. Lisboa: Actual, 2005. p. 133148.

BAUMAN, Z. Modernidade líquida. Tradução Plínio Dentzien. Rio de Janeiro: Zahar, 2001.

BAUMAN, Z. Vida líquida. Tradução Carlos Alberto Medeiros. Rio de Janeiro: Zahar, 2007.

BAUMAN, Z. 44 cartas do mundo líquido moderno. Tradução Vera Pereira. Rio de Janeiro: Zahar, 2011.

CHOULIARAKY, L.; FAIRCLOUGH, N. Discourse in late modernity: rethinking critical discourse analysis. London: Edinburgh University Press, 1999.

DENZIN, N. K.; LINCOLN, Y. S. O planejamento da pesquisa qualitativa: teorias e abordagens. 2. ed. Tradução Sandra Regina Netz. Porto Alegre: Artmed, 2006.

DIAS, R. Gestão ambiental. Responsabilidade social e sustentabilidade. São Paulo: Atlas, 2009. 
DIAS, R. Marketing ambiental. Ética, responsabilidade social e competitividade nos negócios. São Paulo: Atlas, 2011.

ESTY, D. C.; WINSTON, A. S. O verde que vale ouro. Como empresas inteligentes usam a estratégia ambiental para inovar, criar valor e construir uma vantagem competitiva. Tradução Ana Beatriz Rodrigues. Rio de Janeiro: Elsevier, 2008.

FAIRCLOUGH, N. Discurso e mudança social. Coord. da trad.: I. Magalhães. Brasília: Editora da Universidade de Brasília, 2001.

FAIRCLOUGH, N. Analysing discourse: textual analysis for social research. Londres: Routledge, 2003.

FAIRCLOUGH, N. Language and globalization. London and New York: Routledge, 2006.

FAIRCLOUGH, N.; FAIRCLOUGH, I. Political discoursal analysis. A method for advanced students. London and New York: Routledge, 2012. GOBÉ, Marc. Brandjam: o design emocional na humanização das marcas. Tradução Maria Clara de Biase. Rio de Janeiro: Rocco, 2010.

HALLIDAY, M. A. K. An introduction to functional grammar. 2. ed. Londres: Arnold, 1994.

HALLIDAY, M. A. K.; MATTHHIESSEN, C. M. I. M. An introduction to functional grammar. 3.ed. London: Hodder Education, 2004.

KRESS, G. Multimodality. A social semiotic approach to contemporary communication. London: Routledge, 2010.

KRESS, G.; VAN LEEUWEN, T. Multimodal Discourse: the modes and media of contemporary communication. London, Arnold, 2001.

--------KRESS, G.; VAN LEEUWEN, T. Reading Images. The grammar visual design. London; New York: Routledge, 2006.

VAN LEEUWEN, T. Discourse and practice: new tools for critical discourse analysis. New York: Oxford University Press, 2008. 
VAN LEEUWEN, T. The language of colour: an introduction. London: Routledge, 2011.

VIEIRA, J. A.; FERRAZ, J. A. Percursos e avanços do texto multimodal: novas perspectivas na contemporaneidade. Discursos Contemporâneos em Estudo, Brasília, v. 1, n. 1, 2012.

Recebido em março de 2013 Aprovado em agosto de 2013 